\title{
The Role of Multiple-dimensional Microstructure in the Low Adhesion and Superhydrophobicity on the Wing of Tiger Moth (Arctiidae)
}

\author{
Yan Fang ${ }^{\mathrm{a}}$, Gang Sun ${ }^{\mathrm{b}^{*}}$, Wanxing Wang ${ }^{\mathrm{c}}$ and Jingshi Yin ${ }^{\mathrm{d}}$ \\ School of Life Science, Changchun Normal University, Changchun 130032, China \\ afangyan124@aliyun.com, bsungang@nenu.edu.cn, c1481399783@qq.com, d634229991@qq.com
}

\begin{abstract}
The micro-morphology of the moth wing surface was characterized by a scanning electron microscope (SEM). The contact angle (CA) and sliding angle (SA) of water droplet on the wing were measured by an optical CA meter. The wetting mechanism was discussed from the perspective of biological coupling. The moth wing surface is of superhydrophobicity (CA 142 157 ${ }^{\circ}$ ) and low adhesion (SA $1 \sim 4^{\circ}$ ), and displays multiple-dimensional rough microstructure including primary structure (scales), secondary structure (longitudinal ridges and lateral bridges) and tertiary structure (stripes). The scales play a crucial role in the complex wettability of the wing. In micro-dimension, the smaller the width and the bigger the spacing of the scale, the stronger the hydrophobicity of the wing surfaces. In nano-dimension, the smaller the height and the smaller the width and the bigger the spacing of the longitudinal ridge, the stronger the hydrophobicity of the wing surfaces. The average rate of $\mathrm{CaCO}_{3}$ pollution removal from the wing surface is as high as $87.6 \%$. There is a positive correlation $(R=0.8837)$ between pollution removal rate and roughness index of the wing surface. The cooperation of chemical composition and micro-morphology contributes to the special wettability and outstanding self-cleaning performance of the wing surface. The moth wing can be employed as a template for biomimetic design and preparation of novel interfacial material with multi-functions.
\end{abstract}

Keywords: Adhesion, Wettability, Microstructure, Moth, Biomaterial.

\section{Introduction}

Wetting of solid substrates by liquids is one of the most important properties widely used by technological applications. Surface wettability depends basically on the surface roughness and the free energy [1]. In the recent years, the interfacial materials with desirable characteristics have attracted more and more attention due to the wide applications in industrial, military, engineering and domestic fields [2]. After long-term natural selection, many creatures have evolved peculiar body surfaces to adapt to the environment. Insect wing, one of the most complicated three-dimensional periodical substrate in nature, has become a popular template for biomimetic preparation of functional materials. In the current work, the role of hierarchical micro-morphology in the complex wettability of moth wing surface was investigated. The results may bring insight for design and fabrication of novel intelligent materials.

\section{Materials and Methods}

\subsection{Materials}

The moth specimens of ten species in Arctiidae were collected in Changchun City, Harbin City and Jilin City, China. The wings were cleaned, desiccated and flattened, then cut into $5 \mathrm{~mm} \times 5 \mathrm{~mm}$ pieces from the discal cell (Fig. 1).

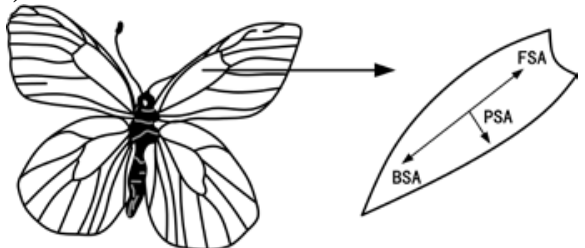

Fig. 1 The experimental area and the SAs in different directions on the moth wing surface 


\subsection{Methods}

After gold coating by an ion sputter coater (Hitachi E-1045, Japan), the wing pieces were observed and photographed by a SEM (Hitachi SU8010, Japan). Using Photoshop software, the micro-morphological parameters of the wing surfaces were measured in the SEM images.

Using an optical CA measuring system (DataPhysics OCA20, Germany), the CA of water droplet $(5 \mu 1)$ on the wing was measured by sessile drop method. The SA of water droplets was measured along three different directions, including forward SA (FSA, the SA of droplet from wing base to wing terminal end), backward SA (BSA, the SA of droplet from wing terminal end to wing base) and perpendicular SA (PSA, the SA of droplet perpendicular to the major axis of wing) (Fig. 1). The water droplet was dripped on the sample table in a horizontal position, then the inclination degree of the table was raised $1^{\circ}$ each time until the droplet rolled off freely. The inclination degree of the table was recorded as the SA value.

After grinding finely, 5 8 mg of wing samples were mixed homogeneously with $200 \mathrm{mg}$ of $\mathrm{KBr}$ and pressed into a thin slice. The absorbance was measured by means of FT-IR (Nicolet FT-IR200, USA). The chemical composition of the wing surface was analyzed by the FT-IR spectra.

The wing pieces were affixed to glass slides with double-sided adhesive tape, and put on the sample table of OCA20. Five mg of $\mathrm{CaCO}_{3}$ particles $(\Phi 5 \sim 10 \mu \mathrm{m})$ were evenly spread on the discal cell of the wing. A water droplet from an injector fell on the $\mathrm{CaCO}_{3}$ area. The sample table was inclined $3^{\circ}$, and the droplet flowed through the contaminated area. A stereo microscope (Zeiss SteREO Discovery V12, Germany) was used to observe the removal of $\mathrm{CaCO}_{3}$ particles.

\section{Results and Discussion}

\subsection{The Effect of Scale on Hydrophobicity and Adhesion of the Wing Surface}

The moth wing surface exhibits hierarchical rough structures made up of primary structure (the micrometric scales) [Fig. 2(A)], secondary structure (the submicro longitudinal ridges and lateral bridges on the scales) [Fig. 2(B)] and tertiary structure (the nano stripes on the longitudinal ridges and lateral bridges) [Fig. 2(C)]. The cross-section of the longitudinal ridge is triangular.

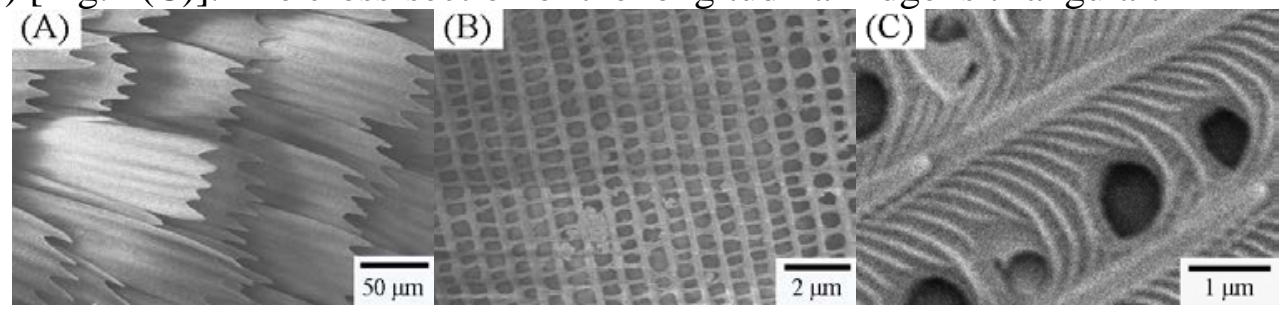

Fig. 2 The multiple-dimensional rough micro-morphology of the wing surface (SEM)

(A) Primary structure (scales); (B) Secondary structure (longitudinal ridges and lateral bridges); (C) Tertiary structure (stripes).

The wing surfaces are highly hydrophobic (CA $142 \sim 157^{\circ}$ ), the average value is $150^{\circ}$ (Table 1 ). Meanwhile, the water SAs on the wing surfaces are extremely small (FSA $1 \sim 4^{\circ}$, BSA $6 \sim 12^{\circ}$, PSA $\left.4 \sim 9^{\circ}\right)$ (Table 1). There are significant differences between the SAs in various directions $(p<0.01)$. The asymmetrical sliding behavior of water droplet on the wing surface ascribes to the anisotropic micro-morphology and the different energy barriers. The moth wing surface, just like the lotus leaf and the rice leaf [3], exhibits high hydrophobicity and low adhesion; while some other natural surfaces like the peanut leaf and the rose petal exhibit high hydrophobicity and high adhesion [4]. The distinct complex wettability results from the different micro-morphologies. The scales play a crucial role in the wetting behavior of droplet on the moth wing. In a contrast test, the scales were removed from the wing surfaces. The CA decreases by $22.3 \% \sim 40.7 \%$, all the SAs (FSA, BSA, PSA) increase above $65^{\circ}$ (the maximum inclination angle of the sample table is $65^{\circ}$ ). 
Table 1 Micro-morphological parameters and wettability of the moth wing surfaces

\begin{tabular}{|c|c|c|c|c|c|c|c|c|c|c|c|c|c|}
\hline \multirow{2}{*}{ Species } & \multicolumn{3}{|c|}{ Scale $(\mu \mathrm{m})$} & \multicolumn{3}{|c|}{$\begin{array}{l}\text { Longitudinal ridge } \\
(\mu \mathrm{m})\end{array}$} & \multicolumn{2}{|c|}{$\mathrm{CA}\left({ }^{\circ}\right)$} & \multicolumn{3}{|c|}{$\begin{array}{c}\text { Measured SA } \\
\left({ }^{\circ}\right)\end{array}$} & \multirow{2}{*}{$\begin{array}{c}\text { Removal } \\
\text { rate of } \\
\mathrm{CaCO}_{3} \\
\text { particle } \\
(\%)\end{array}$} & \multirow{2}{*}{$\begin{array}{c}\text { Roughness } \\
\text { index }(R I) \\
\text { of wing } \\
\text { surface }\end{array}$} \\
\hline & $\begin{array}{l}\text { Length } \\
\text { (a) }\end{array}$ & $\begin{array}{l}\text { Width } \\
\text { (b) }\end{array}$ & $\begin{array}{l}\text { Spacing } \\
\text { (c) }\end{array}$ & $\begin{array}{l}\text { Height } \\
\text { (d) }\end{array}$ & $\begin{array}{l}\text { Width } \\
(e)\end{array}$ & $\begin{array}{l}\text { Spacing } \\
\quad(f)\end{array}$ & Measured & Predicted & FSA & BSA & PSA & & \\
\hline Agylla gigantea & 232 & 103 & 134 & 1.20 & 0.84 & 1.81 & 153 & 155 & 2 & 8 & 6 & 89.4 & 3.2 \\
\hline Arctia caja & 364 & 85 & 100 & 0.85 & 0.92 & 1.52 & 147 & 150 & 3 & 7 & 5 & 86.5 & 2.8 \\
\hline Camptoloma interiorata & 241 & 108 & 99 & 0.92 & 0.97 & 1.75 & 150 & 153 & 3 & 7 & 4 & 88.3 & 3.2 \\
\hline Phragmatobia fuliginosa & 282 & 82 & 85 & 0.47 & 0.76 & 1.65 & 149 & 151 & 3 & 10 & 7 & 85.6 & 2.4 \\
\hline Spilarctia caesarea & 308 & 78 & 98 & 0.54 & 0.85 & 1.83 & 157 & 153 & 2 & 6 & 8 & 91.2 & 3.4 \\
\hline Spilarctia japonensis & 175 & 64 & 146 & 0.66 & 0.72 & 1.89 & 146 & 142 & 4 & 12 & 8 & 86.8 & 2.3 \\
\hline Spilarctia melansoma & 163 & 83 & 102 & 0.58 & 0.66 & 2.36 & 152 & 149 & 2 & 8 & 7 & 84.5 & 2.1 \\
\hline Spilarctia subcarnea & 325 & 95 & 120 & 0.92 & 0.62 & 1.84 & 155 & 157 & 1 & 6 & 4 & 90.7 & 2.9 \\
\hline Spilosoma menthastri & 227 & 68 & 148 & 0.87 & 0.97 & 1.67 & 152 & 150 & 3 & 7 & 8 & 88.7 & 2.8 \\
\hline Spilosoma niveus & 272 & 83 & 104 & 1.22 & 0.74 & 2.23 & 142 & 147 & 4 & 11 & 9 & 84.1 & 1.8 \\
\hline Average & 259 & 85 & 115 & 0.82 & 0.80 & 1.86 & 150 & 150 & 3 & 8 & 7 & 87.6 & 2.7 \\
\hline
\end{tabular}

Note: $R I=\sqrt{\frac{4 d^{2}}{e^{2}}+1}$, where $d$ and $e$ represent height and width of the longitudinal ridge, respectively.

\subsection{The Relationship between Hydrophobicity and Micro-morphology of the Wing Surface}

The moth wing surface is relatively rough with superhydrophobicity and heterogeneity. A composite contact is formed between the droplet and the surface. The contact behavior of a water droplet can be described by the Cassie-Baxter equation:

$$
\cos \theta_{c}=\phi_{s} \cos \theta_{e}+\phi_{s}-1
$$

where $\theta_{c}$ is the apparent CA of a droplet on a composite surface, $\emptyset_{s}$ is the area fraction of solid $\left(0<\emptyset_{s}<1\right.$, calculated from micro-morphological parameters of the wing surface), $\theta_{e}$ is the intrinsic CA of water on an ideal flat surface (approximately $95^{\circ}$ for the moth wing). The contact state of a water droplet on the micro/nano structure of the wing surface is shown in Fig. 3.

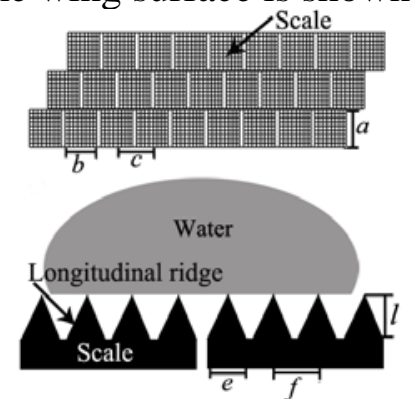

Fig. 3 The contact state of a water droplet on the micro/nano structure of the wing surface

In this case, Eq. (1) can be modified for the theoretical (predicted) CA $\left(\theta_{t}\right)$ as follows:

$$
\cos \theta_{t}=\sqrt{\frac{4 d^{2}}{e^{2}}+1} * \frac{b e}{c f} * \cos \theta_{e}+\frac{b e}{c f}-1
$$

Based on Eq. (2), the predicted CAs were calculated (Table 1). Taking predicted CAs as independent variable $y^{*}$, measured CAs as dependent variable $y$, the degree of fitting was judged by:

$$
\begin{aligned}
Q & =\sum\left(y-y^{*}\right)^{2} \\
R_{\mathrm{New}} & =1-\left(Q / \sum y^{2}\right)^{1 / 2}
\end{aligned}
$$

where $Q$ is sum of square of deviations, $R_{\mathrm{New}}$ is the coefficient of determination in nonlinear regression equation. The calculated $R_{\mathrm{New}}$ values are $0.922 \sim 0.963$ for the ten species of moth. There is no significant difference between the measured CAs and the predicted CAs, demonstrating the micro-morphological model for hydrophobicity is in good accord with the Cassie-Baxter equation. In the light of Eq. (2), the smaller the values of $\sqrt{\frac{4 d^{2}}{e^{2}}+1}$ and $\frac{b e}{c f}$, the bigger the theoretical CAs. Namely, in micro-dimension, the smaller the width and the bigger the spacing of the scale, the stronger the hydrophobicity of the wing surfaces; in nano-dimension, the smaller the height and the smaller the 
width and the bigger the spacing of the longitudinal ridge, the stronger the hydrophobicity of the wing surfaces. Naturally hydrophobic material such as chitin is the chemical foundation for the high hydrophobicity on the moth wing. Much higher hydrophobicity, however, cannot be induced by the chemical composition alone. Superhydrophobicity of the wing surfaces is attributed to a cooperation of hydrophobic material and rough micro-morphology.

\subsection{The Relationship between Self-Cleaning Property and Micro-morphology of the Wing Surface}

Due to the rough structures on the wing surface, most contaminating particles settle on the tips of microtextures, the actual contact area between particle and microstructure is very small. The adhesive force between particles and water droplet is much larger than that between particles and wing surface, thus the particles can be "trapped" and taken away easily by the rolling droplet. The particle removal rate has no significant correlation $(R<0.15)$ with the scale parameters (length, width, spacing) or the longitudinal ridge parameters (height, width, spacing), but has significant correlation $(R=0.8638)$ with roughness index $(R I)$ of the wing surface. $R I$, the magnitude of surface roughness, is the ratio of the real area to the geometry projection area. The superhydrophobicity and self-cleaning characteristic of the wing surface ascribes to the coupling effect of hydrophobic material and rough structure. The self-cleaning function endows the moth with the ability to lighten body burden, increase flight efficiency and optimize energy budget. Thus, the moth can get more opportunities to survive.

\section{Conclusions}

The moth wing surface displays hierarchical micro-morphology including primary, secondary and tertiary structure. The wing surface is of low adhesion (SA $1 \sim 4^{\circ}$ ) and high hydrophobicity (CA $142 \sim 157^{\circ}$ ). The scales play a crucial role in the complex wettability of the wing. In micro-dimension, the smaller the width and the bigger the spacing of the scale, the stronger the hydrophobicity of the wing surfaces. In nano-dimension, the smaller the height and the smaller the width and the bigger the spacing of the longitudinal ridge, the stronger the hydrophobicity of the wing surfaces. On the wing without scales, the CA decreases by $22.3 \% \sim 40.7 \%$, the SA increases above $65^{\circ}$. The average rate of $\mathrm{CaCO}_{3}$ particle removal from the wing surface is as high as $87.6 \%$. There is a good positive correlation $(R=0.8837)$ between pollution removal rate and roughness index of the wing surface. The coupling effect of hydrophobic material and rough microstructure contributes to the special wettability and excellent self-cleaning characteristic of the wing. The moth wing can serve as a template for biomimetic design of micro-controllable superhydrophobic surface and nano dust-free coatings. This work not only promotes our understanding of wetting mechanism of natural surfaces, but may offer inspirations for development of novel interfacial material with multi-functions.

\section{Acknowledgments}

This work was financially supported by the National Natural Science Foundation of China (Grant No. 31671010) and the Innovative Program for Postgraduates of Changchun Normal University (Grant No. cscxy2017003, cscxy2017006). Dr. Prof. Gang Sun is the corresponding author of this paper.

\section{References}

[1] S.T. Wang, L. Jiang, Definition of superhydrophobic states, Adv. Mater. 19 (2007) 3423-3424.

[2] Y. Fang, G. Sun, T.Q. Wang, Q. Cong, Hydrophobicity mechanism of non-smooth pattern on surface of butterfly wing, Chin. Sci. Bull. 52 (2007) 711-716.

[3] L. Feng, S.H. Li, Y.S. Li, H.J. Li, L.J. Zhang, J. Zhai, Y.L. Song, B.Q. Liu, L. Jiang, D.B. Zhu, Super-hydrophobic surfaces: from natural to artificial, Adv. Mater. 14 (2002) 1857-1860.

[4] X. Yao, Y.L. Song, L. Jiang, Applications of bio-inspired special wettable surfaces, Adv. Mater. 23 (2011) 719-734. 